\title{
Mercado de Trabalho: uma velha questão e novos dados
}

\author{
Antônio Virgílio P. Bastos* \\ *Professor adjunto do Departamento \\ de Psicologia/UFBa. e coordenador da \\ pesquisa "Tendềncias de emprego \\ en Psicologia"/CFP.
}

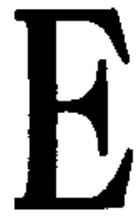

studas sobre mercado de trabalho, no geral, sāo raros no Brasil. Estatísticas mais amplas e seguras sobre 0 mercado de trabalho, embora sejam 70 mil em exercício, representam uma parcela insignificante da populaçăo economicamente ativa (PEA) e não aparecem, enquanto categoria, nas estatísticas oficiais. Assim, dados abrangentes sobre a situação de emprego da categoria sto escassos e inexistem pesquisas que acompanhem, ao longo do tempo, como se comportam as variáveis determinantes do emprego do psicólogo (forças que atuam na sua absorçăo ou năo). Tais consideraçōes levaram o CFP a planejar a realizaçăo, a cada très anos, por ocasião das eleiçסes nos Conselhos Regionais, de um lavantamento para caracterizar as condiçōes de emprego do psicólogo no país. O primeiro levantamento ocorreu em 1989. São estes dados que estamos devolvendo à categoria, neste momento, e que funcionarăo como um referencial nos próximos levantamentos. Só assim, poderemos acompanhar as transformaçסes que ocorrem em nivel do trabalho prestado pela categoria e ter acesso a dados que apoiem as políticas a serem desenvolvidas pelos seus órgãos representativos, permitindo alguma forma de intervençào na realidade de mercado.

Comoafirma Novaes (1970), aquantidade e qualidade dos empregos fornecidos pelo mercado de trabalho de pendem da intensidade da atividade econômica e das tecnologias em uso. Embora seja comum pensar-se que o mercado, automaticamente, regula 0 volume de emprego e distribui os indivíduos de forma mais adequada, na realidade sua açăo traduz decisóes políticas, conscientes ou năo. Tais decisóes políticas, que integram quaisquer políticas econômicas, moldam o mercado de trabalho quando interferem em fatores que condicionam a intensidade da atividadeeconômica (por exemplo, disponibilidade financeira) e as tecnologias utilizadas. Vale assinalar que uma política de formação de mão-de-obra é um dos componentes de uma política econômica mais ampla e envolve a intervençăo do estado na fixaçăo de metas e alocaçăo de recursos para o 
desenvolvimento de pessoal qualificado em áreas julgadas necessárias.

No caso do Brasil, como assinalam Chahad e Luque (1984), mesmo no periodo de intenso crescimento econômico, "a taxa de absorçāo da mãode-obra era substancialmente menor e insuficiente para absorver o crescimento de oferta de trabalho. Esta absorção, já naquela época, pressionava o mercado de trabalho gerando desemprego aberto, como também subemprego" (p. 25). Este quadro se agrava, sensivelmente, com as políticas de ajuste econômico implementadas ao longo dos anos $80 \mathrm{e}$ que buscaram, seguindo orientação do Fundo Monetário Internacional, combater a inflação crescente através da recessăo. O mercado de trabalho é o lugar para onde convergem todas as conseqüências da adoçđo da recessão como mecanismo de combate aos problemas econômicos vividos pelo país. $\dot{E}$ ainda Chahad e Luqueque, baseados na experiência recessivado início dosanos 80 , traçam um quadro do mercado de trabalho cuja característica básica foj aprofundada radicalmente pela atual política econômica governamental: "a adoçāo de políticas de estabilizaçāo tem se mostrado extremamente perversa com relação aos níveis de emprego. Estes têm caído continuamente desde o início da década (anos 80). Pode-se afirmar que o desemprego é generalizado no país tanto em termos setoriais quanto em regiōes, principalmente urbanas. Praticamente todos os segmentos populacionais estāo atingidos, sendo colocados no desemprego até mesmo pessoal de alto nível de qualificação". (p. 25).

$A$ análise de mercado de trabalho centra-se, normalmente, em duas dimensðes básicas: a quantidade de emprego e o valor (remuneração), segundo Novaes (170), fatores que analisaremos adiante. Todavia, a diversidade de atuação do psicólogo (autônomo $\mathrm{x}$ assalariado, atuando em segmentos diversos do mercado indústria, comércio, setor público e privado-e prestando serviços diversificados) tornam mais complexa a tarefa de exame da situaçāo de mercado de trabalho. Assim, além dos dois fatores classicamente analisados, incluimos no presente trabalho, uma terceira dimensăo de análise: a modalidade do trabalho em si que é prestado pelo profissional.

Neste artigo, a análise da situação do psicólogo no mercado de trabalho será relacionada com a sua formação acadêmica. Mais especificamente, discutiremos em que medida psicólogos que se formaram em instituiçōes diferentes (particulares, públicas e confessionais) se posicionam diferentemente no mercado, nas três dimensōes acima assinaladas. Tal questāo nos parece relevante por duas razōes: primeira, pela inexistência de uma avaliação dessa natureza, apoiada $\mathrm{em}$ dados nacionais; segundo, pela expectativa teórica de que egressos dessas distintas instituiçőes formadoras poderiam refletir, no seu trabalho, as condiçōes e políticas diversas que as caracterizam.

Duas informações preliminares nos parecem importantes para contextualizar os dados que apresentaremos adiante.

Primeiro, trabalhamos com uma amostra de 1424 profissionais, distribuídos por 21 unidades da Federação, residentes nas capilais estaduais $(77,9 \%)$ e em cidades do interior, sendo $85,7 \%$ do sexo feminino, com idades variando entre 22 e 65 anos (média de 33,6 anos) e um tempo médio de graduado de 7,51 anos.

Segundo, obtivemos dados de psicólogos egressos de praticamente todas as instituiçōes formadoras no país. Essas instituiçбes foram agrupadas em quatro categorias conforme a natureza do seu

Tabela 01 - Inserção no mercado de strabalho de Psicologia por natureza da instituição formadora.

\begin{tabular}{|l|c|c|c|c|c|}
\hline \multicolumn{1}{|c|}{ Inserção } & \multirow{2}{*}{ Total } & \multicolumn{2}{c|}{ I. Públicas } & \multicolumn{2}{|c|}{} \\
\cline { 4 - 6 } & & Federal & Estadual & Confessionais & Particulares \\
\hline $\begin{array}{l}\text { Trabalha atualmente em } \\
\text { Psicologia }\end{array}$ & 84.5 & 85.7 & 87.4 & 87.0 & 82.2 \\
\hline $\begin{array}{l}\text { Não trabalha em Psicologia, } \\
\text { mas já trabalhou }\end{array}$ & 9.2 & 9.9 & 9.7 & 8.3 & 9.1 \\
\hline $\begin{array}{l}\text { Nunca trabalhou em } \\
\text { Psicologia }\end{array}$ & 6.3 & 4.4 & 2.9 & 4.7 & 8.8 \\
\hline \begin{tabular}{l} 
Total \\
\hline No de casos
\end{tabular} & 100.0 & 100.0 & 100.0 & 100.0 & 100.0 \\
\hline
\end{tabular}

* inclui os casos em que a instituição de formação não foi indicada 
regime jurídico. A seguir apresentamos essas categorias discriminando-se as instituiçōes que tiveram maior participação quantitativa na composiç̧o dos grupos: instituiçōes públicas estaduais (91 casos, provenientes, sobretudo da USP, FFCL de Assis-SP, Universidade Estadual de Londrina, USP-Ribeirão Preto, Universidade Estadual de Maringa); instituiçðes públicas federais (207 casos oriundos principalmente das Universidades Federais da Bahia, Rio Grande do Norte, Pernambuco, Minas Gerais, Paraná, Ceará, Pará, Uberlândia/MG e da Universidade de Brasília); instituiçđes confessionais ( 408 casos provenientes sobretudo da Católica de Goiás, PUCRS, PUC-SP, Católica do Paraná, Católica de Pernambuco, MetodistaSP, Católica-MG, PUC-Campinas); instituiçōes particulares ( 662 caos, oriundos principalmente do CEUB-DF, São Marcos-SP, FMU-SP, FAFIRE-MG, Paulistana-SP, Tuiti-PR, Ojetivo-SP, Gama Filho-RJ).

\section{A inserção no mercado de trabalho}

Os primeiros dados referem-se à questāo central numa análise destẹ tịpo: 0 emprego e desemprego. Embora existam divergências quanto ao que se considera como desemprego (o IBGE não inclui nas suas estatísticas de desempregados aqueles que desistiram de procurar o emprego naquele momento da pesquisa; o DIEESE, pelo contrário, inclui esta parcela de "desencorajados" ao calcular os seus índices de desem. prego), no levantamento realizado, partimos do pressuposto de que os profissionais que mantinham o seu vínculo com o Conselho - a populacão investigada - constituíam a força de trabalho efetiva, sendo isto um indicador do seu interesse em continuar sendo psicólogo, estivesse ou não em busca de emprego na área naquele momento da pesquisa. Fizemos, todavia, uma distinção entre aqueles que, não estando trabalhando em psicologia, já tinham ou nạo traba. thado em uma das suas areas.

A tabela 1 apresenta estes dados dis. criminados por tipo de instituiçăo formadora.

Como podemos observar, encontramos, mesmo entre os inscritos nos CRPS., um contingente de $15,5 \%$ de profis. sionais nạo exercendo a profissão para a qual se graduaram. Este percentual é ligeiramente maior entre os egressos de instituiçōes particulares, aproximando-? se de $18 \%$. Este contingente (cujas projeçōes nos levam a falar de cerca de dez mil profissionais inscritos que näo

\begin{tabular}{|c|c|c|c|c|c|}
\hline \multirow{2}{*}{ Tipo de trabalhos } & \multirow{2}{*}{ Total } & \multicolumn{2}{|c|}{ I públicas } & \multirow{2}{*}{ Confessionais } & \multirow{2}{*}{ Particulares } \\
\hline & & Federal & Estadual & & \\
\hline $\begin{array}{l}\text { Trabalha apenas } \\
\text { em psicologia }\end{array}$ & 73.4 & 76.7 & 78.0 & 77.0 & 69.5 \\
\hline $\begin{array}{l}\text { Trabalha em } \\
\text { psicologia e fora }\end{array}$ & 11.1 & 10.7 & 7.7 & 10.0 & 12.7 \\
\hline $\begin{array}{l}\text { Trabalha apenas } \\
\text { fora da psicologia }\end{array}$ & 10.1 & 6.8 & 12.1 & 7.6 & 12.0 \\
\hline Não trabalha & 5.4 & 5.8 & 2.2 & 5.4 & 5.8 \\
\hline Total & 100.0 & 100.0 & 100.0 & 100.0 & 100,0 \\
\hline № de casos & $(1421)^{*}$ & (206) & (91) & (408) & (662) \\
\hline
\end{tabular}

* inclui os casos em que a instituição de formação não foi indicada

exercem,efetivamente, a psicologia no pais) é bastante significativo, considerando-se tratar-se de uma profissða de nível superior que demandous um longo periodo de formaçăo e investimentos dos individuos. Este constitui o nosso contingente de "desempregados", certamente superiot aos indices de desemprego no país, quando se consideram as estatisticas oficiais.

Outro dado importante é o índice de quem, mesmo graduado, nunca chegou a trabalhar em psicologia (neste caso, ele é bem mais elevado entre os egres. sos das escolas particulares * chega a $8,8 \%$, indice quase $100 \%$ superior aos observados entre os egressos das demais instituigues. Possivelmente tais dados devem-se, principalmente ${ }_{2}$ a fatores restritivos do mercado embora, em estudo anterior, tenhamos encontrado que o ingresso no curso de psi- cologia, cm vários casos, nâ alende a uma busca de profissionalizaçào. (Carvalho, Ulian, Bastos, Sodré, Cavalcante, 1988).

Mesmo aqueles que se encontram trabalhando no campo, muitas vezes combinam esse trabstho com outros fora dapsicologia, o que é um indicador adicional das restriçoes do mercado. Os dados que podem ser vistos na tabela 2 revelam que, para um pouco mais de 1/4 da amostra, năo existe uma dedicoça exclusiva à profisstăo que escolheram, incluindo-se aí os que năo trabalhavam ou o faziam fora do campo da psicologia.

Tambem neste caso podemos observar quo, entre os profissionais egressos de escolas particulares, encontra-se um percentual mais baixo dos que atuam exclusivamente en psicologia e o maior percentual dos que năo possuem qualquer 
trabalho. Neste grupo, qualse $1 / 4$ dos psicólogos tem um trabaliho fora da psicologia. $O$ índice de desemprego "real" $E$, nesse grupo e raquele constituido por pricótogos egresiso de escolas públicas federais, mais do que o dobro do observado entre as egressos de universidad poblikes estadiutis. As implicaçôs destes dados sto granites: quando constatamos que e o esmento pivivado o que gradua mation hirmero de pisicólogos no parars.

A manurencto de un trabalho ford pode ser vista, certantente, como ant indicador claro de insergato precánia no mercado de psicologit; os rendiritentess

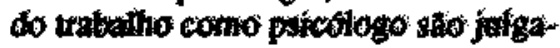

dos, provavelmente, insuficientes para manter o profissional totalmente dedicado a prof issto que escolhea, Oexame da natureza deste trabalho fora', que veremos adiantery sos dera a oportanidade de verificar em que nível ele pode ser tomado como um indicador da fragilidade do mercado de trabaltho, tanto por sita natureza propriamente dita, como pelos rendimentos que proporcionam ao profissional.

Sto sintertias de problemas de mercado; ainda, os seguintes dados: quase $20 \%$ dos psićfogos do sexo masculino contingm un emiprego dentro cont outro forta dia psicofogra (esté percentual é 0 doture do encentrado entre as mutheres);
Tabela 03 - Número de trabalhos no campo de Psicologia por instituição de formação

\begin{tabular}{|c|c|c|c|c|c|}
\hline \multirow{2}{*}{ Número de traballios } & \multirow{2}{*}{ Total } & \multicolumn{2}{|c|}{ I. Públicas } & \multirow{2}{*}{ Confessionais } & \multirow{2}{*}{ Particulares } \\
\hline & & Federal & EstaduaI & & \\
\hline \multicolumn{6}{|l|}{ Trabalha só em psicologia } \\
\hline apenas 1 trabalho & 67.5 & 57.6 & 67.6 & 66.2 & 71.3 \\
\hline dois trabalhos & 28.0 & 36,1 & 29.6 & 28.0 & 25.0 \\
\hline três ou mais trabalhos & 4.5 & 6.4 & 2.8 & 5.8 & 3.7 \\
\hline Total & 100.0 & 100.0 & 100.0 & 100.0 & 100.0 \\
\hline $\mathrm{N}^{2}$ de casos & $(1041)^{*}$ & (158) & (71) & (311) & $(456)$ \\
\hline \multicolumn{6}{|c|}{ Trabalha em psicologia e fora } \\
\hline um trabalho & 78.7 & 85.7 & ** & 72.5 & 78.3 \\
\hline dois trabalhos: & 21.3 & 14.3 & $\star \star$ & 27.5 & 21.7 \\
\hline Total & 100.0 & 100.0 & ** & 100.0 & 100.0 \\
\hline $\mathrm{N}^{\circ}$ de casos & $(155)^{*}$ & (21) & (07) & $(40)$ & (83) \\
\hline
\end{tabular}

* inclui os casos em que a instituiçấo de formaçấo nấo foi indicada $* * \mathrm{n}<20$ o que se atribui à demanda social para o que homem ganthe mais e assuma niaiores encirgos na famflia, ainda presente em hossa sociedade de forma bem forte; contrariamente, é mais de duas vezes superior o percentual de mutheres sem qualquer trabalho, quando comparadas com os homens. Esses dados refletem uma caracteristica marcante do miercado de trabalko, năo so brasileiro - a sua clara segmentação por sexo (que veremos mais adiante quando analisarmos os rendimentos), presente mesmo quando analisamos uma "profissao predominantemente feminina".

Ainda nesta dimenswo "quantitativa" do estudo do mercado, fazemos uma análise do número de traballios em psícologia executados, cujos dados encontram-se na talbela 3 .

Parte significativa dos que só atuam na profissäo mantén um so trabalho; entretanto, cerca de $1 / 3$ deste contingente tem dois ou mais empregos. $O$ que levaria um psicólogo a manter mais de un trabalho em psicologia? Embora náo tenhamos: respostas coniclusiva a esta indagaçao, nao podemos atribuir exclusivamente a dificuldades do mercado esta busca e manuterçầ de outros trabalhos em psicologia. Cono diseutimos em outra oportunidade (Bastos; 1989) existe um modelo de atuaçăo profissional muito forte que confunde atuaçăo psicológica com atividade clínica, $A$ força deste modelo explica parcela significativa do movirnento do psicólogo ao longo da sua carreira entitie as áreas de atuação. A clínica exerce maior poder de atraçăo; sendo o tipo de atividade mantida mais freqüentemente em paraleloa trabalhos em outras áreas. Um indicador da atração exercida pela clínica, no presente estudo, pode ser observado nos seguintes dados: $50,4 \%$ dos trabalhos secundários são na área clínica (o psicólogo, mesmo atuando em outra área mantém um vínculo, embora precário en termos de carga horáriaeremuneraçăo, comaatividade. clínica) muitas vezes a atividade ctinica foi colocada como o trabaltho principal embora o tratalho secundário proporcionasse maier renda e absorvesse maior quantidade de tempo semanal.

Neste aspecto, os egressos de instituicoes pablicas federtis's; quando comparados com os dentatis, apresentain maior número de enitipegos entic pstcolegia (42,5\% tem pelo nerios dois trabalhos en psicologia quando a media geral fica en torno d* $32 \%$ ).

Artlés de passamos a análise da di: menssao remiuneraçä/rendimentos, cremos ser importante caractorizar o enprego fora da psicologia mantidos por 302 psicólogos da amostra estudada. 


\begin{tabular}{|c|c|c|c|}
\hline Locais & $\%$ & Atividades & $\%$ \\
\hline Empresa & 30.4 & $\begin{array}{l}\text { Técnico-burocráticas } \\
\text { administrativas }\end{array}$ & $\begin{array}{l}40.2 \\
14.2 \\
\end{array}$ \\
\hline Escola & 16.6 & $\begin{array}{l}\text { secretaria/recepção } \\
\text { supervisão }\end{array}$ & $\begin{array}{l}7.1 \\
6.1\end{array}$ \\
\hline Órgăo Adm. Pública & 12.1 & $\begin{array}{l}\text { bancário } \\
\text { escriturário }\end{array}$ & $\begin{array}{l}6.0 \\
3.7 \\
\end{array}$ \\
\hline Banco & 11.5 & $\begin{array}{l}\text { outras } \\
\text { Ensino-técnicas }\end{array}$ & $\begin{array}{r}3.1 \\
19.9 \\
\end{array}$ \\
\hline Residência & 9.1 & $\begin{array}{l}\text { docência } \\
\text { outras }\end{array}$ & $\begin{array}{r}12.4 \\
7.5 \\
\end{array}$ \\
\hline Hospital/C.Saúde & 3.7 & $\begin{array}{l}\text { Proprietários } \\
\text { comerciante }\end{array}$ & $\begin{array}{r}15.3 \\
8.5 \\
\end{array}$ \\
\hline Inst. Ensino Superior & 3.7 & $\begin{array}{l}\text { empresário } \\
\text { fazendeiro } \\
\text { Funcooes nivel superior }\end{array}$ & $\begin{array}{r}6.1 \\
.7 \\
14.6 \\
\end{array}$ \\
\hline Orgáos assistenciais & 3.0 & $\begin{array}{l}\text { Assessoria/gerência } \\
\text { técnicos }\end{array}$ & $\begin{array}{l}8.1 \\
6.5 \\
\end{array}$ \\
\hline INAMPS & 2.4 & $\begin{array}{l}\text { Funçōes sem qualificação formal } \\
\text { Funçoes ligadas à arte }\end{array}$ & $\begin{array}{l}5.3 \\
4.6\end{array}$ \\
\hline SESC/SENAC & 1.4 & 60 & \\
\hline Centro Pol. Militar & 1.0 & 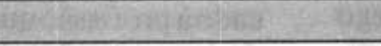 & - \\
\hline outros & 5.1 & 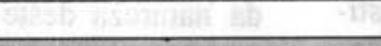 & \\
\hline Total & 100.0 & Total & 100.00 \\
\hline
\end{tabular}

Daremos uma atenção especial a essas informaçōes por se tratar do primeiro estudo de âmbito nacional que levanta este tipo de dado.

A tabela 4 apresenta a distribuiçăo de psicólogos por local de trabalho e tipo de atividade desenvolvida.

Aproximadamente $2 / 3$ deste grupo trabalha em empresas, escolas, órgãos públicos e bancos. Há uma grande variedade de atividades desenvolvidas por este grupo de psicólogos. Nesta diversidade (que vai do trabalho de doceira à assessoria parlamentar, de transcrição de fitas a exercício de mandato como vereador) podemos distinguir seis gnupos de atividades ocupacionais: o mais freqüente $(40,2 \%)$ envolve atividades técnico-burocráticas que demandam formação đe até segundo grau, exemplo de ocupaçōes como secretária, recepcionista, serviços bancários, serviços administrativos em geral. $\mathrm{O}$ segundo grupo $(19,9 \%)$ inclui as atividades de ensino tais como alfabetização, ensino no primeiro grau, além đe outras ocupaçōes técnicas a exemplo de auxiliar de enfermagem, instrumentação cirúrgica, técnico em computação. $O$ terceiro grupo (15,3\%) é constituído por psicólogos que possuem o seu próprio "negócio", sendo proprietários de empresas, lojas e fazendas. $O$ quarto grupo $(14,6 \%)$ inclui atividades que requerem o nível superior, sendo exercidas por aqueles que buscaram a psicologia após terem se graduado em outras áreas, tais como, enfermeira, sanitarista, médico, advogado, pedagogo. O quinto grupo $(5,3 \%)$ envolve atividades que nāo demandam uma qualificação formal e sim o domínio de alguma habilidade específica a exemplo de vendedor/balconista, costureira, doceira, marceneiro. O último grupo $(4,6 \%)$ inclui atividades ligadas à arte tais como, ator, músico, fotografia, pintura, artesanato/decoração.

A distribuição destes psicólogos por instituiç̧åo formadora e a remuneração média que auferem destas atividades podem ser vistas na tabela 5.

Tabela 05 - Tipo de atividades fora da Psicologia por instituição de formação.

\begin{tabular}{|c|c|c|c|c|}
\hline Atividades fora & Total & $\begin{array}{c}\text { I.Públicas* } \\
\text { (Feder. Estad.) }\end{array}$ & Confessionais & Particulares \\
\hline Técnico-burocráticas & 40.2 & 39.6 & 35.9 & 43.3 \\
\hline Ensino e técnicas & 19.9 & 29.2 & 18.8 & 18.5 \\
\hline Proprietários & 15.3 & 10.4 & 20.3 & 15.3 \\
\hline Funções nivel superior & 14.6 & 10.4 & 17.2 & 12.7 \\
\hline Funções "sem qualificação formal" & 5.3 & 6.2 & 3.1 & 5.7 \\
\hline Funções ligadas à arte & 4.6 & 4.2 & 4.7 & 4.5 \\
\hline Total & 100.0 & 100.0 & 100.0 & 100.0 \\
\hline $\mathrm{N}^{2}$ de casos & $(281)^{\star *}$ & $(48)$ & (64) & $(157)$ \\
\hline
\end{tabular}

* foram agregadas instituições estaduais e federais pelo reduzido número de casos da primeira.

** inclui casos em que a instituição de formação não foi indicada. 
O predomínio de atividades administrativo-burocráticas mantém-se entre egressos de todos os grupos de instituiçoes. A seguir, aparecem os psicblogos que exercem atividades de ensino ou outras funçōes técnicas de segundo grau, cujo percentual é bem mais elevado entre os egressos das instituiçoes públicas (aqui englobando federais e estaduais). Encontram-se, entre os egressos das instituiçōes confessionais, os maiores índices de psicólogos que se mantêm atuando em outras profissóes de nível superior e que são proprietários. Quando comparamos as diversas regióes do país, dado que não aparece em tabela, poucas diferenças merecem destaque; entre elas a de que no Sul e em seguida no Nordeste, encontram-se percentuais um pouco mais elevados dos que desenvolvem atividades que năo exigem escolaridade formal (grupo 5), enquanto no Sudeste há a maior concentração daqueles que se dedicam paralelamente a atividades artísticas.

Quanto à remuneração, os rendimentos médios por grupos de atividades revelam uma realidade esperada: as atividades ligadas à arte e ao ensino apresentam os rendimentos mais baixos, inclusive em relaçăo àqueles obtidos pelas "atividades sem qualificaçāo formal". Em oposição, a média de rendimentos é três vezes maior entre os que exercem outra atividade de nível superior e quase cinco vezes entre as atividades empresariais. Estas diferenças explicam, certamente, porque apenas $15 \%$ dos "empresários" e $28,9 \%$ dos que exercem outra profissāo de nível superior querem deixar esta atividade, percentual que cresce para $65,5 \%$ entre os que desempenham ocupaçōes técnicoburocráticas. Outro dado interessante é que $50 \%$ dos que mantêm "atividades não qualificadas" pretendem persistir nelas.

\section{A remuneração}

Informaços iniciais sobre o valor dos rendimentos obtidos pelos psicólogos em seus trabalhos no campo da psicologia podem ser vistas na distribuiçào de profissionais por faixas de rendimentos, constante da figura 1.

$O$ contingente de $22,4 \%$ de psicólogos sem rendimentos inclui os desempregados e aqueles que só traballham fora da psicologia e representa parcela expressiva da categoria. Nas demais faixas, como se percebe e é esperado, a distribuiçăo dos rendimentos do emprego principal (ou único) mostra-se mais deslocada para o extremo nega-

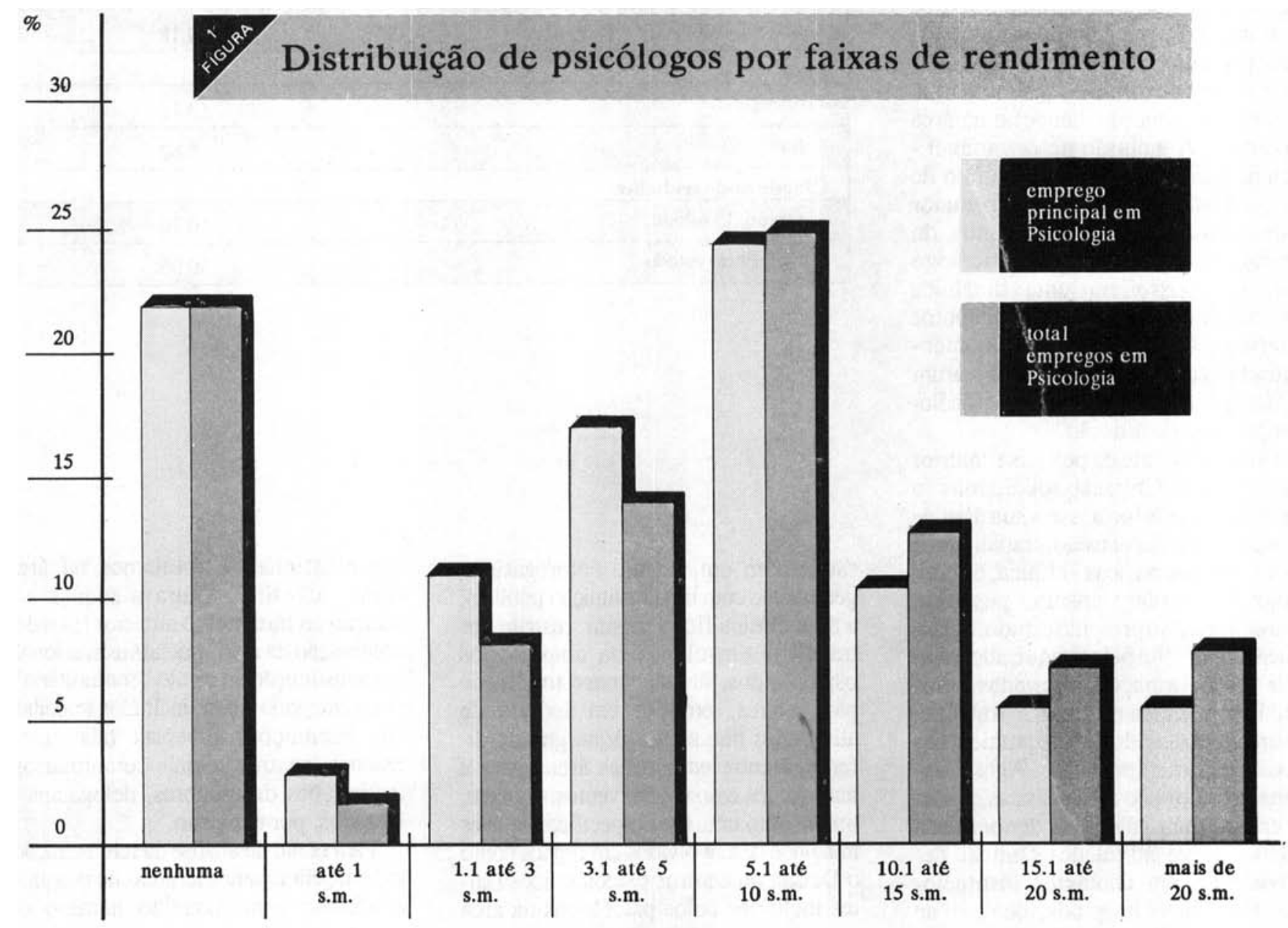


tivo do que a distribuiçăo dos rendimentos totais em psicologia. Neste caso, a faixa de 5 a 10 salários mínimos (s.m.) é a que absorve maior número de psicólogos, vindo, a seguir, as faixas imediatamente próximas. Na realidade, oque mais chama a nossa atençåo $e$ o contingente de profissionais que recebem até 3 s.m. (chega a aproximadamente $10 \%$, mesmo agregando-se os trabalhos secundários em psicologia), revelandoser significativo o que poderíamos chamar de subemprego na profissão. Tal dado, explica, certamente, o fato de expressivo número de psicólogos manterem uma atividade fora da profissato. Vale lembrar que nesta faixa salarial situa-se a grande massa de trabalhadores brasileiros que năo apresenta qualificaçăo fórmal, revelando a precariedade da inserça do de parcela importante dos psicóloges. Quando sabemos que este quadro não se restringe à psicologia, estendendo-se a outras profissoes de nível superior, algumas até mais tradicionais, temos a visăo clara da desordem que reina no mercado de trabalho brasileiro, onde níveis educacionais elevados não se traduzem, necessariamente, em melhores postos e remuneraça para quem os possui.

Para uma compreensła mais rigorosa do quadro de rendimentos, esses dados foram trabalhados considerando-se tanto a instituiçăo formadora quanto a area de atuaçăo. Existe claramente no pafs, uma profunda segmentacho do mercado entre as profissóes que atuam na área socjal (eduaçăo, saúde) e na área produtiva. A inclusāo desta variável área de atuaça - prende-se ao fato de ela permitir visualizar, com maior clareza, os múltiplos segmentos do mercado em que se insere o psicólogo que, por possuirem uma dinâmica própria, condicionam os rendimentos auferidos. Assim, cabe, neste momento, esclarecer os criterios que nortearam a classificaçăo dos trabialhos dos psicólogos por área de atuaçăo.

Diferentemiente da pesquisa anterior realizada pelo CFP, não solicitamos ao psicólogo que informasse a sua área de atuaçăo; naquela ocasiāo, traballıamios com seis áreas básicas - clínica; organizacional, escolar, ensino, pesquisa, comunitária. Nopresente estudo; aclassificaç̃o foi feita pelo pesquisador com base en informaçoes prestadas pelos psicologos acerca do local de trabalho, natureza do vínculo empregatícioe nas atividades desemperihadas. Agora, traballhainos com oito áreas básicás, teniose criado uma categoria denominada "sauide" (para atividades clínicas desenvolvidas em contextos institucionais tais como hospitais, centros de

\begin{tabular}{|c|c|c|c|c|c|}
\hline \multirow{2}{*}{ Áreas } & \multirow{2}{*}{ Total } & \multicolumn{2}{|c|}{ I. Públicas } & \multirow{2}{*}{ Confessionais } & \multirow{2}{*}{ Particulares } \\
\hline & & Federal & Estadual & & \\
\hline Clínica $(n=438)$ & 9.93 & 8.52 & 14.02 & 12.29 & 8.30 \\
\hline $\begin{array}{l}\text { Organizacional } \\
(n=289)\end{array}$ & 12.87 & 9.60 & 14.18 & 16.70 & 11.03 \\
\hline Escolar $(n=95)$ & 5.15 & 6.56 & 5.70 & 5.25 & 4.50 \\
\hline Social $(n=94)$ & 5.17 & 5.71 & 6.19 & 5.27 & 4.96 \\
\hline Ensino $(n=80)$ & 11.03 & 9.22 & 19.31 & 13.91 & 6.70 \\
\hline Saúde $(n=87)$ & 4.66 & 3.44 & 6.31 & 5.30 & 4.13 \\
\hline Média & 8.97 & 7.90 & 12.37 & 11.46 & 7.76 \\
\hline № de casos & (1070) & (159) & (75) & (321) & (515) \\
\hline
\end{tabular}

\begin{tabular}{|l|c|}
\hline \multicolumn{1}{|c|}{$\begin{array}{c}\text { Tabela } 07 \text { - Média de rendimento considerando todos os trabalhos em psicologia } \\
\text { por instituicão de formação, sexo e local de residêncla/trabalho. }\end{array}$} \\
\hline \multicolumn{1}{|c|}{ Instituições formadoras } & $\begin{array}{c}\text { rendimento médio } \\
\text { (em salários mínimos) }\end{array}$ \\
\hline pública federal & 9.66 \\
\hline pública estadual & 13.52 \\
\hline confessional & 11.96 \\
\hline particulares & 9.18 \\
\hline Sexo & \\
\hline masculino & 13.17 \\
\hline feminino & 9.62 \\
\hline Cidade onde trabalha & \\
\hline capital do estado & 10.16 \\
\hline interior do estado & 10.06 \\
\hline
\end{tabular}

satide com um vinculo empregatiotio,

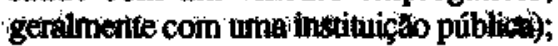
a frea clfinica fieou, assim, restrita wos trabalhos em clftica ou consulobrios psicológicos, na stia quase toibilidade particulares, enibora en termos the ativitadies năo se werifique grande difercnipa entre essis duas áreas para a maicia dos casos. Resolvemos, whibem,

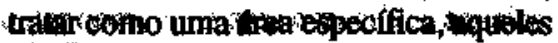
tralbälhos desenvölvidos em árgas conto o. Detran ou centros peicotécricos (antes incluídos pelos psicólogos na área organizacional) e rotulamos tal área como "trânsito". Outra mudança em relaçà ao tratkamento anterior foi a denominacto da trea "social/institucional" en substituição à of́ulo "comnunitária"; nesta categoria foram incluidos trabailhos em instituiçoes diversas tais como creches, centros sociais-comtunitários, instiunifoes de mengres, delegacias e jutsedos, por eremplo.

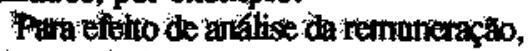
codavia, eliminamos as aireas de pesquisa e trânisito pelo reduzido número de 


\begin{tabular}{|l|c|c|}
\hline \multicolumn{1}{|c|}{ Tabela 08 - Rendimento médio, em salários mínimos, dos trabalhos dentro e fora da Psicologia, por área de atuação. } \\
\hline Clínica & Rendimento em Psicologia & Rendimento fora da Psicologia \\
\hline Organizacional & 5.51 & 7.76 \\
\hline Escolar & 6.62 & 5.26 \\
\hline Social & 4.59 & 5.38 \\
\hline Ensino & 3.67 & 10.18 \\
\hline Saúde & 4.36 & 9.53 \\
\hline
\end{tabular}

sujeitos, ficando com as seis áreas que absorvem quantidades mais expressivas de profíssionais. Os resultados, vistos na tabela 6, revelam diferenças significativas tanto por áreas quanto por instituiçăo formadora, quando comparamos os rendimentos do emprego principal ou único.

Quanto as instituiçoes formadoras, os egressos das instituiçðes públicas estaduais apresentam maior remuneração média (12,37 s.m.), próxima aquela obtida pelos que se graduaram em instiuiços confexsionais (11,46 s.m.). Esses dois grupos se distanciam bastante dos dois outros: egressos de escolas particulares $(7,76$ s.m.) e instituiços públicas federais (7,90 s.m.). Quanto ds áreas, em sintonia com dados de pesquisas anteriores (Pasquali, 1988), a área organizacional aprescenta os maiones rendimentos médios, independente de instituiç̧o de graduafăo (12,87 s.m. na média, chegando a 16,7 s.m. entre os egressos de instituiçoes confessionais). Em segundo lugar vem a área de ensino cuja média de $11,03 \mathrm{~s}, \mathrm{~m}$. é fortemente condicionada pelos rendimentos auferidos pelos que atuam nesta área provenientes de instituiçoes públicas estaduais e confessionais, na sua maioria professores universitários. A terceira área, a clínica, com média de 9,93 s.m., também apresenta rendimentos médios superiores entre os egressos das instituiçoes públicas estaduais econfessionais. As tués áreas restantes apresentam médias de remuneraçăo bem inferiores, em torno de cinco salários mínimos, sendo o grupo que atua na área de saúde, especialmente se egressos de escolas particulares e públicas federais, o que obtém pior remuneraçăo (respectivamente 4 e 3 salários mínimos, em média).

Quando analisamos o rendimento total em psicologia (somando-se as remuneraçסes do trabalho principal e a dos secunđários para quem os possuía), as tendências nåo se alteram quanto a instituiçăo de origem, como podemos ver na tabela 7.

A média de rendimentos cresce para 10,41 s.m. e a ordem entre instituiçóes permanece a mesma já comentada. Outros dados importantes na tabela 7 referem-se ao rendimento médio por sexo e cidade em que trabalha. Nðo foram encontradas diferenças significativas entre quem atua nas capitais e no interior (remuneraçă média en tomo de $10 \mathrm{~s} . \mathrm{m}$.) enquanto a diferença por sexo é bastante acentuada (os homens com médias de $13,7 \mathrm{~s} . \mathrm{m}$. e as mulheres com 9,62). A segmentação do mercado por sexo, já observada em relaçăo aos aspectos quantitativos também aparece na dimenș̃o qualitativa (remuneraça).

Os dados seguintes referem-se ao grupo de psicólogos que possuem, além de trabalho(s) em psicologia algum trabalho fora. Como vemos na tabela 8, as médias de remuneraçăo em psicologia sto bem mais baixas, em todas as áreas, do que as que observamos na tabela 6 quando temos as médias de todos os profissionais. Verificamos também que, à exceçåo das áreas organizacional $\mathrm{e}$ saúde, os trabalhos fora apresentam remuneraçăo média bem superior. Isso ocorre, especialmente, entre os que trabalhavam em ensino e saúde.

A manutençăo de um trabalho fora da psicologia, cono hipotetizamos anteriormente, prende-se, claramente, à insuficiência dos rendimentos do trabalho como psicólogo sugerindo, novamente, a fragilidade ou restriçăo de seu mercado de trabalho.

Ainda referente a este grupo de psicólogos, percebemos também que o salário fora da psicologia, na média geral, representa 3,18 vezes o que aufere

\begin{tabular}{|c|c|c|c|c|c|}
\hline \multirow{2}{*}{ inserção } & \multirow{2}{*}{ Total } & \multicolumn{2}{|c|}{ I. Públicas } & \multirow{2}{*}{ Confessionais } & \multirow{2}{*}{ Particulare } \\
\hline & & Feder. & Estad. & & \\
\hline amostra total & 46.6 & 35.3 & 64.7 & 50.0 & 46.6 \\
\hline $\begin{array}{l}\text { só trabalha fora } \\
\text { da Psicologia }\end{array}$ & 54.9 & 42.9 & 72.7 & 63.3 & 52.6 \\
\hline $\begin{array}{l}\text { trabalha dentro e } \\
\text { fora da Psicologia }\end{array}$ & 34.2 & 23.8 & 42.9 & 32.5 & 38.6 \\
\hline
\end{tabular}



QUADRO 01 - CARACTERÍSTICAS DOMINANTES DO TIPO DE SERVIÇO PRESTADO PELOS PSICÓLOGOS POR
ARREA DE ATUAÇÃO E INSTITUÇÃo DE FORMAÇÃO

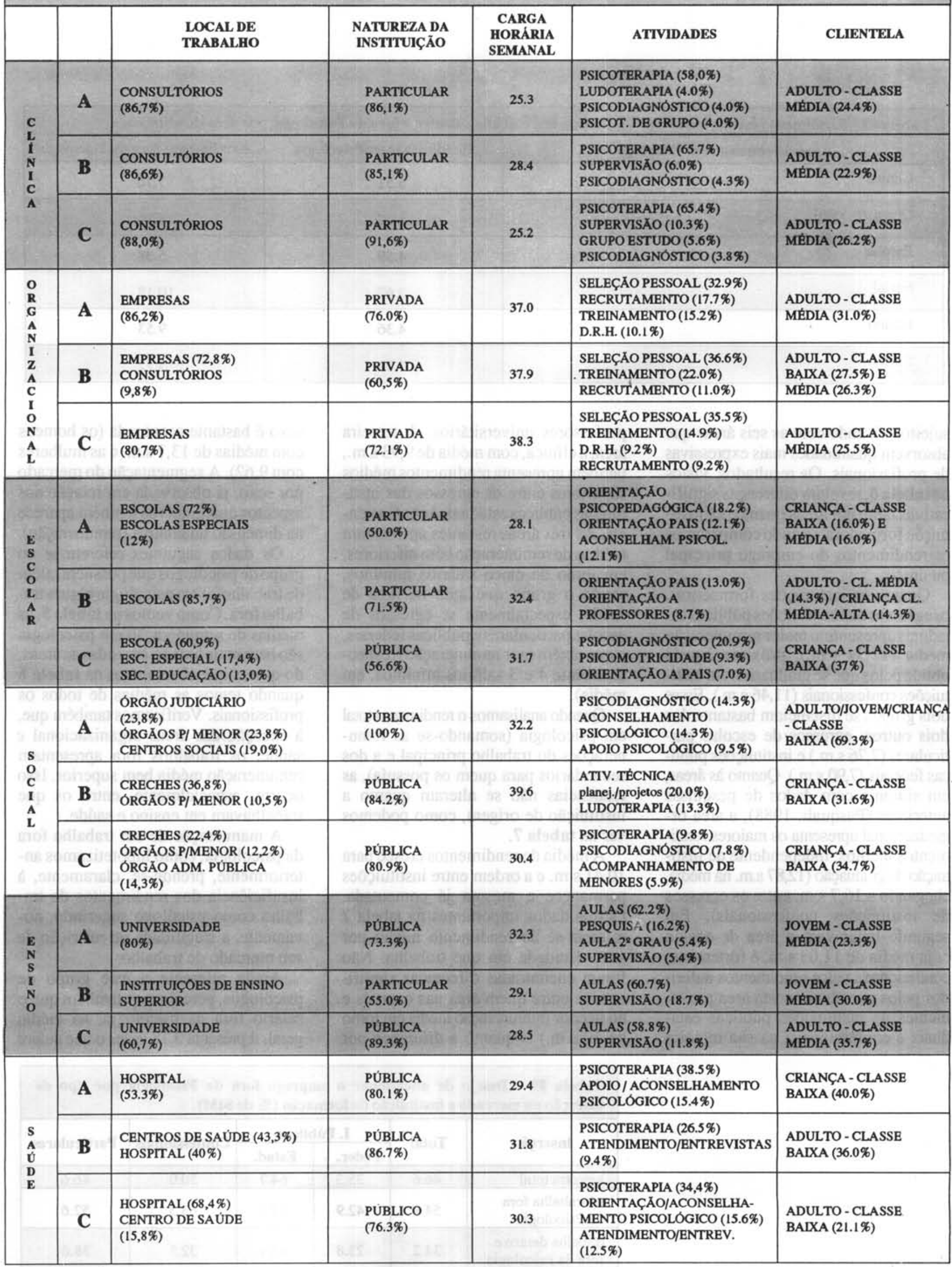


com o exencício da profissăo; esta média é superior entre os egressos de escolas públicas federais $(3,81)$ e particulares $(3,61)$, sendo mais reduzido entre os que segraduaram em instituiçóes públicas estaduais $(, 65)$. $O$ peso do salário fora é ambém superior entre as mulheres $(3,52)$ do que entre os homens $(2,26)$.

Tais dados, quando agregados àqueles referentes ao índice de emprego/desemprego, nos mostram alguns segmentos da categoria razoavelmente diferenciados: os egressos de escolas particulares e públicas federais apresentam maior dificuldade de inserção no mercado e, quando inseridos, os trabalhos săo mais precários em termos de remuneracajo, o que os leva a buscar ou manter, em maior proporçăo, empregos fora da psicologia. As mulheres quando comparadas com o reduzido grupo de homens $(13,9 \%)$ que integra a categoria, também apresentarn condiçóes mais precárias de inserção. Aqui é importante retomar o dado de que a composiçăo do grupo de egressos de instituiçốes ptiblicas federais ficou fortemente influenciada por profissionais do CRP-02 e CRP-03, podendo esta realidade descrita refletir, adicionalmente, as dificuldades de inserção do psicólogo na regiāo Nordeste. Neste particular, este grupo se distancia daquele de egressos de escolas públicas estaduais, na sua maioria oriundos de instituiçōes paulistas e parangenses. Este grupo apresenta, tambem, os maiores percentuais de psicólogos con cursos de pós-graduacão strictu-senso, outro fator que pode explicar a sua média de rendimentos mais elevada. Os egressos de instituiçoes particulares, apesar de apresentarem os maiores percentuais de cursos de especializaç to e formação terapêutica mostram uma média de rendimento bem mais baixa.
A satisfaçăo com tais condiçoes pode ser inferida a partir dos dados sobre o desejo de deixar o emprego fora, dedjcando-se exclusivamente à psicologia, dados que podemos ver na tabela 9.

É ligeiramente superior à metade, o contingente dos que não pretendem deixar esta fonte adicional de remuneração fora da psicologia; ele chega a quase $2 / 3$ daqueles que têm emprego dentro e fora da psicologia, sendo mais reduzido entre os que so trabalham fora da psicologia. Novámente, aqui, o pessoal egresso das instituiçōes federais apresentam os menores índices de desejo de mudança $(23,8 \%$ entre os que atuam dentro e fora e $42,9 \%$ entre os que só trabalham fora) revelando uma descrença quanto a conseguirem uma inserção enquanto psicólogos suficientes para atendimento as suas necessidades ou, por outro lado, uma satisfaçăo profissional com a atividade que desenvolvem fora dapsicologia.Considerando-se a natureza predominante destas atividades, como vimos, podemos inferir que tais dados revelam um vínculo precário com a profissåo, produto de uma formaçăo deficiente aliada às condiçôes de mercado difíceis. É interessante observar que o grupo egresso de instituiçőes públicas estaduais apresenta um perfil bastante diferenciado, mesmo entre aqueles que mantêm um emprego fora da psicologia - 0 índice de intenção de deixar tal trabalho é elevado, sobretudo entre os que só trabalham fora da psicologia.

\section{A natureza do serviço prestado}

O presente estudo, embora lidando com uma amostra menor de profissionais, traça um perfil do tipo de serviço pestado pelo psicólogo muito similar ao conseguido na pesquisa anterior, realizada pelo Conselho Federal. Portanto, năo nos deteremos demasiadamente neste item; na realidade, apresentamos a seguir um quadro que sintetiza as tendências dominantes do tipo de trabalho por instituiçåo formadora, análise que também năo empreendemos na pesquisa anterior. Vejamos, assim, as informaçð̃es constantes no quadro 1.

Tomando-se cada área de atuação, discriminamos no quadro 1 dados dos grupos egressos das instituiçðes públicas (federais e estaduais), confessionais e particulares quanto ao local de trabalho, natureza da instituiçāo, carga horária média semanal, principais atividades desenvolvidas e clientela mais freqüentemente atendida.

A área clínica, independente da instituiçăo formadora de origem, caracteriza-se pela atuaçăo em consultórios particulares, como trabalhos de tempo parcial onde a psicoterapiać a atividade largamente dominante, predominando o atendimento a pessoas adultas de classe média. O trabalho na área organizacional ocorre basicamente em empresas privadas, como um trabalho de tempo integral, onde seleção, recrutamento e treinamento de pessoal sto as atividades mais freqüentes. A área de ensino $\varepsilon$ integrada basicamente por professores universitários de instituiçōes de ensino públicas (entre os egressos das instituiçöes confessionais predominam escolas privadas) desenvoivendo, sobretudo, atividades de ensino e supervisðo (apenas entre os egressos de instituiçð̌es públicas e que atuam no setor público, a pesquisa aparece como uma atividade frequiente). A área educacional envolve o trabalho em escolas, predominantemente particulares (apenas entre os egressos das instituiç̧̋es particulares, o trabalho em escolas públicas superou o de escolas privadas) e caracteriza-se pelo atendimento a crianças (quando a atividade principal e psicodiagnóstico ou orientação psicopedagógica) ou a adultos (no caso de orientaçăo a pais). $\mathrm{Na}$ área social há maior diversidade de locais de trabalho, predominando creches (públicas e particulares) entre os egressos de instituições particulares e confessionais e orgãos do poder judiciário entre os egressos de instituiçōes públi- 
cas. Associada à diversidade de local existe, também, maior diversidade de atividades que, muitas vezes, nâ se distinguem da atividade clínica (psicodiagnósticos, psicoterapia, aconselhamento psicológico). Finalmente, a área de saúde caracteriza-se pela inserção em hospitais ou centros de saúde da rede pública, $o$ atendimento $a$ indivíduos de nível súcio-econômico baixo, mas com atividades mais frequientes que năo se distinguem da atividade clínica tradicional.

O que mais impressiona neste quadro é que o modelo de atuação revela-se basicamente o mesmo, independente do tipo de instituiçăo em que o psicólogo se graduon. Ou seja, o mercado de trabalho, agora visto sob o prisma do tipo de trabalho oferecido à sociedade, revela-se bastante homegêneo, indicando que as instituigóes formadoras têm atuado como reprodutoras de um modelo básico de atuacăo que consiste no desempenho de tarefas tradicionalmente confiadas aos psicólogos, nos seus diversos ambientes de trabalho. As discussoes e mudanças que têm sido implementadas em diversas instituicóes de ensino, ainda năo geraram mudanças significativas no padrão de serviços prestados pelo psicólogo.

\section{Algumas reflexões finais sobre os dados}

É complexa a tarefa de se fazer uma avaliaçắo do quadro apresentado anteriormente, sobretudo no que se refere às dimensớes clássicas de análise do mercado de trabalho (índice de emprego e remuneraçđo) por vários motivos. Primeiro, a diversidade de modalidades de inserçăo profissional do psicólogo - ora como autônomo, ora comoempregado; ora comoempregado de setores mais dinâmicos da economia, ora como funcionário público atuando na área social, aí incluindo-se as atividades de ensino e pesquisa. São segmentos de mercado muito diferenciados cujas políticas de emprego e remuneraçầ possuem características e determinantes específicos. Segundo, pela ausência de parâmetros externos, por exemplo, dados de outras categorias similares, com base nos quais pudéssemos fazer um julgamento mais realístico dos dados disponíveis, não calcado, apenas, nas nossas expectativas e desejos.

Tais dificuldades não nos impede, todavia, de constatar, com certa facilidade, a existência de distorçoes e problemas com a inserç̧̆o do psicólogo no mercado. Independente de parâmetros externos de julgamento, considerandose exclusivamente o fato de lidarmos com uma profissão de nivel superior que demanda pelo menos cinco anos de formaçăo, é preocupante o indice dos que sequer ingressam no mercado de psicologia ou ofazem de forma extremamente precária, através de subempregos que o obrigam a manter outras atividades remuneradas. Tałvez este năo seja um problema específico da psicologia já que reina no Brasil, uma desordem absoluta em termos de remuneracta da força de trabalho, com desequilibrios gritantes tanto em nivel regional quanto em relação ao valor da remuneração como funçăo da qualificaça do profissional. Sđa distorçoes históricas que têm se acentuado absurdamente nosúltimos anos em função da política econômica que tem sob controle, apenas, os salários.

$\mathrm{Na}$ realidade, existem forças extrinsecas e intrínsecas à profissăo determinando o quadro que descrevemos anteriormente.

A política recessiva, de forte contenção do poder aquisitivo dos salários, afeta diretamente a condiçăo do psićlogo enquanto assalariado, mesmo quando isso ocorre em setores produtivoś, como é o caso do psicólogo organizacional. Ai temos a situação em que o psicólogo mais se aproxima do con- ceito de empregado, com trabalhos de tempo integral, embora se insira nas empresas em uma das subáreas menos valorizadas e mais sensivel à crise económica - o setor de recursos humanos. Este impacto é sem dúvida maior, quando se trabalha nas áreas sociais, normalmente no serviço público que tradicionalmente adota uma política de remunerar indignamente seus servidores (por descaso ou deliberadamente, numa política de afirmar a incompetência do estado e abrir espaços para o setor privado?). Neste segmento o quadro se torna agudo com a crise do estado política e econômica - e a estagnaçăo dos serviços públicos (apesar da crescente demanda de serviços pelo contingente pobre da populaça). A ampliaça do mercado e das condiçoes de remuneração dos psicólogos, como outros profissionais da área social, dependem da ampliacão dos serviços públicos; on seja, de o estado assumir, efetivamente, deliberaçoes constitucionais que asseguram educacaso, saúde e assitencia à populaçẳo. Em síntese, as dificuldades da pancela assalariada se devem basicamente, à crise econômica estrutural, agravada profundamente nos anos 80 ,e ao estado năo se responsabilizar, efetivamente, pela implantaçăo de un polftica social que amplie 0 acesso da parcela pobre da populagão a beneficios restri- 
tos aos segmentos abastados.

A situraça de crise econômica é um poderoso condicionante externo, também, para o segmento autớnomo da categoria, ao pauperizar a classe média, reduzindo o seu poder de acesso aos serviços psicológicos. A crescente concentracto de renda, a progressiva perda de poder aquisitivo dos salarios (mesmoem setores económicos modernos e mais imunes a recessa) diminui a clientela potencial do psicólogo. A adogabo de politicas recessivas tem como consequências, năo apenas o desemprego aberto e o engajamento em atividades de baixa produtividade, como afimam Chahad e Luque (1984): "há uma scentuada queda do salário real, agravanento do perfil de disuibuiça de renda e deterioracio das condiçôes de viele da grande maioria da populachio. A redistriburictio de salarios tem comprimido a renda da classe média, com consegüencia sobre a demanda dos setores conde ela $\phi$, tradicionalmente, a principal cliente". (p. 23). Além da retomada do crescimento económico, a longo prazo, a smpliacto do acesso a servipos psicológicos depende da elevacto do nivel sócio-cultural da populagto, traduridu en uma maior preocupacto con sua sarde psicológica.

Existe, sincha, um outro fator externo (6e mexado) que nllo pode ser minimi- zado ao se discutir as dificuldades enfrentadas pelos psicólogos. $O$ grande contingente da categoria é feminino e existe uma diferenciaçlo profunda do mercado quanto a sexo. Entre as mais importantes transformaçoes da populaça conomicamente ativa brasileira está a crescente participaço feminina. Esta participaçăo cresceu de 17,9\% em 1960 para $34,8 \%$ em 1982, seguindo a trajetória dos países industrializados, embora ainda estejamos em níveis comparáveis aos da Europa em 1960. Todavia, as mulheres invadem o mercado de trabalho "por baixo", atuando em setores pouco privilegiados e mal pagos da economia (Pereira, 1984, p. 31). Um exemplo claro desta realidade podemos ver no caso da atividade de ensino que se tornou, basicamente, uma tarefa feminina; entretanto, enquanto as mulheres representavam, em 1980 , 95,4\% dos professores primários, esta proporçto cafa para $77,6 \%$ entre os professores secundários e para $42,2 \%$ entre os universitários. A segmentaça por sexo observa-se, inclusive, dentro da propria categoria de psicólogos, quando as mulheres apresentam níveis de desemprego maiores e de rendimentos bem inferiores ao do reduzido grupo de homens.

Diante de forgas externas tho poderosas, tho socialmente enraizadas, que forças intrinsecas podem explicar parcela das dificuldades enfrentadas pelo profissional? A resposta, aqui, e certamente parcial e se apoia nas evidencias dos dados apresentados anteriormente. O modelo de profissional colocado no mercado pelas instituiçoes formadoras é além de bastante homogêneo, tradicional. O exame do tipo de inserçato dos psicólogos deixa claro que as instituicóes formadoras năo têm explorado todo o potencial de crescimento e ampliaçåo dos serviços que este profissional pode prestar. Por outro lado, inexiste, face a esta característica, uma política definida de oferta de cursos e vagas. Centenas de psicólogos continuam sendo formados para prestar o mesmo tipo de serviço que caracteriza a sua atusçăo desde a regulementaçăo da profissăo, num contexto sócio-econ6mico de crise que reduz drasticamente a demanda e oportunidades de emprego. Talvez, nfo tenhamos claro, sequer, que caminhos alternativos devem ser percorridos, que atividades inovadoras devem ser desenvolvides, enfim, que modelo novo de profissional deve ser oferecido à sociedade. Neste caso, estamos diante de um outro fator intrinseco que impoe limites: a incapacidade da categoria gerar esses modelos alternativos com o necessiotio impacto. A carencia de profissionais dedicados à pesquisa, a formaçà acadênica em larga medida dissociada da investigaçăo, tếm como consequiencias n⿳亠丷厂 só a precária quatidade dos serviços prestados (a adoçăo cegade técnicas que estao na moda, por exemplo), mas a năo construçăo de modelos de atuaçăo mais apropriados à populaçăo do seu país e as conjunturas de crise que parecem permanentes. Aqui, o círculo se fecha com o descaso do governo para com o ensino superior público onde, bem ou mal, é realizada a maior parte das pesquisas em psicologia no país.

\section{Bibliografia}

1. BASTOS, A.V.B. (1988) Areas de atuaça: em questio o nosso mo. dolo de projissional. Em, CFP. Qwem Co psicólogo brosileiro? Säo Paulo: Edicon, Educ, Sciensia et Labor. p. 163.193.

2. CHAHAD, ...LUQUE, ... (I984) .......

3. CARVALHO, A.A., ULIAN, A.L.O., Bastos, A.V.B., Sadré.L.G.P. e Cavalcante, M.LO.P. (1988). A escolha da profissto: alguns valo. res implicitos nos motivos apontados pelos psicólogos. Em, CFP. Quem éo psicólogo brasileiro? Sāo Paulo: Edicon, Educ, Scientia et Lavor, $p$. 49-68.

4.NOVAES,P.(1970). Educação - trabalho - o futuro dos recursos humanos. Brasilla: $M E C$.

5. PASQUALI, I. (1988) Condiçoes de trabalho do psicologo. Em, CFP. Quem é o psicblogo brasileiro? Säo Paulo: Edicon, Educ, Scientia et Labor, p. 149.162.

6. PEREIRA, R.R. (ed) (1984). A mullier e o trabatho. Retrato do Brasil - da monarquia do estado militar. vol. 3. Séo Paulo: Edtitora Poltaica. 